\title{
Quilombo: a voz do Teatro Experimental do Negro (Rio de Janeiro, 1940/1950)
}

Vanessa Lima Cunha ${ }^{1}$

Resumo: Este artigo propõe uma análise do jornal Quilombo: vida, problemas e aspirações do negro e a sua relação com o mito da democracia racial no Brasil nas décadas de 1940 e 1950. Este jornal foi fruto do trabalho de um grupo teatral denominado Teatro Experimental do Negro (TEN) surgido em 1944, na cidade do Rio de Janeiro. O referido periódico buscava dar voz a todos que tinham uma visão crítica sobre o preconceito racial no Brasil naquele contexto. Procuraremos compreender alguns dos discursos veiculados por este jornal, partindo de estudos e leituras de pesquisadores do tema, e as possibilidades de contribuição que ele deu nos debates relativos ao mito da democracia racial.

Palavras-chave: Jornal Quilombo, Teatro Experimental do Negro, democracia racial, Abdias Nascimento.

O presente artigo busca trabalhar o surgimento do jornal Quilombo: vida, problemas e aspirações do negro e a sua relação com o mito da democracia racial no Brasil nas décadas de 1940 e 1950, partindo de leituras e trabalhos de alguns dos principais pesquisadores desse tema.

\footnotetext{
${ }^{1}$ Este artigo traz a versão resumida de um dos capítulos do meu TCC defendido no ano de 2009, na Universidade Estadual de Londrina, intitulado $O$ Teatro Experimental do Negro e a sua relação com o mito da democracia racial no Brasil, orientado pela profa. Dra Silvia Cristina Martins de Souza.
} 
O Estado Novo teve início em 1937, instalado por Vargas em forma de ditadura com o apoio das forças armadas. Daniela Roberta Antônio Rosa coloca que neste período "algumas manifestações culturais de origem negra, tidas anteriormente como negativas e até símbolos e causadoras do atraso brasileiro, passaram a ser pesadas como expressão de brasilidade." (ROSA, 2007: 68), pois neste período o presidente procurou desenvolver uma política de valorização do brasileiro, mas não se esquecendo de que se tratava de uma ditadura e por isso só eram permitidas as visões do Estado sobre como deveria ser este país e seus cidadãos. E assim como o teatro teve uma função política nos anos 1880 e 1920 , ele também teve nos anos 1940, quando o TEN foi criado.

Este jornal surge como fruto dos trabalhos desenvolvidos pelo grupo teatral denominado Teatro Experimental do Negro (TEN). Os fundadores deste grupo surgido em 1944 buscavam através de suas peças desenvolverem "a valorização social do negro através da educação da cultura e da arte" (NASCIMENTO, 2004: 198)

A figura de Abdias Nascimento é parte fundamental desde grupo, pois foi ele o responsável inicial das ideias e projetos do TEN, e para ele e seus colaboradores o objetivo deste grupo era a inserção e a valorização do negro no teatro e na sociedade brasileira. Como coloca o próprio Nascimento: 
Cadernos de Clio, Curitiba, n. ${ }^{\text {o }}$ 3, 2012

"Teríamos que agir urgentemente em duas frentes: promover, de um lado, a denúncia dos equívocos e da alienação dos chamados estudos afro-brasileiros, e fazer com que o próprio negro tomasse consciência da situação objetiva em que se achava inserido." (NASCIMENTO, 2004: 211)

Desde seu surgimento o TEN, procurou trabalhar e defender determinadas ideias contra o preconceito racial. Para concretização deste projeto o grupo procurava desenvolver, palestras, debates, aulas de alfabetização, aulas referente à cultura negra, concursos de artes plásticas, concursos de beleza, peças teatrais e também a elaboração de um jornal.

O jornal Quilombo foi lançado em 1948, e o propósito do TEN era de usar este espaço para divulgar as suas peças teatrais, mas também utilizar este como meio de desenvolver as suas críticas sobre democracia racial, preconceito racial, assim como a relação entre eles.

É importante fazer então uma breve contextualização sobre o conceito de "democracia racial".

Para a pesquisadora Célia Maria Marinho de Azevedo, em Abolicionismo Estados Unidos e Brasil, uma história comparada (século $X I X$ ), a imagem de um paraíso racial no Brasil, que mais tarde se transformaria na ideia de democracia racial, já vinha sendo construída desde o século XIX por viajantes estrangeiros que 
Cadernos de Clio, Curitiba, n. ${ }^{\text {3 } 3,2012}$

visitaram o Brasil, assim como por abolicionistas brasileiros e americanos. (AZEVEDO: 2003)

Os viajantes e depois os abolicionistas influenciaram muitos os trabalhos elaborados no início do século $\mathrm{XX}$, dentre os quais o de Gilberto Freyre que lançou na década de 1930 um livro chave sobre as relações raciais no Brasil denominado Casa Grande e Senzala. Este autor e sua obra foram durante muito tempo tido como referências nos estudos referentes às "questões raciais", pois ele defendia a ideia de um país onde se vivia uma relação harmoniosa entre brancos e negros.

As ideias defendidas por Freyre passaram a ser questionadas no Brasil a partir de fins dos anos $1950^{2}$, neste período também temos o surgimento do Projeto Unesco. Os primeiros revisionistas da obra de Freyre e das relações senhor e escravo, a saber, Florestan Fernandes, Fernando Henrique Cardoso e Octavio Ianni $^{3}$, dentre outros, acabaram por classificar a ideia de democracia racial como um mito fundador da nação brasileira. Ou seja, eles não acreditavam na relação harmoniosa que fora propagada pelos

\footnotetext{
${ }^{2}$ Com o fim da Segunda Guerra Mundial, a Organização das Nações Unidas para a Educação, Ciência e Cultura (UNESCO), patrocinou uma serie de pesquisas sobre as relações raciais no Brasil. Para mais esclarecimentos ver Marcos Chor Maio, Projeto Unesco e a agenda das Ciências Sociais no Brasil dos anos 40 e 50.
}

3 Alguns destes pesquisadores foram patrocinados em suas pesquisas pela UNESCO e a Revista Anhembi. 
abolicionistas do século XIX e posteriormente por Freyre na década de 1930.

Para eles estas relações teriam sido de tal maneira conflituosas e violentas que privaram os escravos de capacidade de ação, transformando-os em "coisas" (exemplificados pela figura do "Pai João"), só restando aos mesmos uma reação diante da violência que sofriam - a rebeldia-, sendo o exemplo mais acabado desta rebeldia à figura de Zumbi.

Como resultado dessa nova percepção sobre o assunto, a ideia do racismo como componente da sociedade brasileira passou a ser discutido, o que ia de encontro ás ideias construídas por Freyre.

Emília Viotti da Costa esclarece que

"Estes cientistas acumularam uma nova quantidade de evidências de que os brancos no Brasil foram preconceituosos e de que os negros, apesar de não terem sido legalmente discriminados, foram "natural" e informalmente segregados" (COSTA, 1999: 366)

Foi esta a situação que vivenciavam os ex-escravos a partir da abolição, que tem sido lenta e gradualmente modificada até os dias atuais. A partir do que foi dito, pode-se ver que quando o TEN começou suas atividades a ideia de democracia racial estava em pleno auge o que chama uma atenção maior para este grupo.

O objetivo então é compreender quais foram às ações desenvolvidas pelo jornal Quilombo na luta contra o mito da democracia racial. Para verificarmos como essa discussão aparece 
no jornal, iremos utilizar principalmente o artigo de Petrônio Domingues denominado Quilombo (1948-1950) uma política de vozes afro-brasileiras.

O jornal Quilombo apresentou sua primeira edição no dia 09 de dezembro de 1948 na cidade do Rio de Janeiro. Daniela Roberta Rosa nos esclarece que:

Os editoriais eram de autoria de Abdias Nascimento e o periódico tinha como colunas permanentes: Livros, Tribuna estudantil, Escolas de Samba, Cinema, Música, Rádio, Negros na História, Fala A Mulher, [...] Pelourinho, Democracia Racial, Cartaz, Sociais, Close Up e Noticias do teatro Experimental do Negro. Além de um número de matérias assinadas. (ROSA, 2007: 82-83)

A periodicidade deste jornal foi predominantemente mensal, e ele foi "custeado com os recursos advindos de alguns membros do TEN - como Guerreiro Ramos - e de colaboradores brancos." (DOMINGUES, 2008: 264).

Analisaremos agora uma das colunas do jornal Quilombo. $\mathrm{Na}$ coluna do jornal denominada "Arquivo", o artigo ${ }^{4}$ de Raquel de Queiroz questionando o leitor sobre a democracia racial do Brasil, denominado Linha de Cor, como segue,

Será que por ausência de preconceito que quase nenhuma das ordens religiosas existentes no Brasil

\footnotetext{
${ }^{4} \mathrm{O}$ artigo de Raquel de Queiroz foi primeiro publicado no periódico O Cruzeiro, em 24 de maio de 1947. (DOMINGUES, 2008: 266)
} 
recebe pessoas de cor no seu seio - salvos como leigos, que dizer, como criados? E que os colégios grã-finos não aceitam alunos ou alunas de cor? E que a Light (e o governo fecha os olhos ante isso) não admite telefonistas de cor? E que nenhuma loja das ditas elegantes daqui do Rio, de São Paulo e de outras capitais, emprega vendedores de cor? Já viu manicuras e cabeleireiras de cor nos salões de beleza de luxo? Leu no livro de Mário filho o que foi a batalha para se introduzirem jogadores negros nos clubes de futebol carioca? Sabe que nenhum bar da área atlântica, em Copacabana, permite que se sente às suas mesas algum freguês de cor? $\mathrm{E}$ que a restrição era feita no cassino - e ainda é feita em certas "boites" ou cabarés de alta sociedade? E que tanto o hotel Serrador como outras hospedarias de alto bordo adotam como linha de conduta não tolerar hóspedes de cor... [...] Se isso não é discriminação racial - e, mais grave ainda, discriminação admitida e amparada pelo governo - que nome lhe daremos? (Quilombo, dez de 1948 p.2. Apud DOMINGUES, 2008: 265-266)

O questionamento feito no final do artigo, por essa escritora, é uma questão muito emblemática, e para Nascimento e seu grupo este era um ponto que deveria se trabalhar mais, pois como acreditava o grupo, o negro no Brasil sempre foi discriminado em praticamente todos os campos da sociedade, e por isso eles acreditavam que este debate poderia vir a ajudar na luta contra o preconceito racial, assim como ajudaria na divulgação e ampliação no combate contra os limites impostos as pessoas de cor no Brasil.

Para Domingues "o artigo de Raquel de Queiroz traçava um painel panorâmico do regime não declarado de segregação racial a que o negro ficava exposto em vários lugares do Brasil, na 
década de 1940." (DOMINGUES, 2008, p. 266) Os pontos levantados por Queiroz como restrições nas ordens religiosas, em colégios ditos "grã-finos", lojas de roupa, salão de beleza, bares dentre outros exemplos, retratam alguns dos pontos contra os quais o TEN procurou lutar durante todo o tempo não só nas paginas do jornal Quilombo, mas também através das peças teatrais, palestras, aulas, como ditas anteriormente.

Nascimento e o TEN procuravam contestar a ideia de democracia racial no Brasil utilizando principalmente o jornal Quilombo, como porta-voz, sobretudo na coluna "Democracia Racial”. A primeira matéria escrita nesta coluna foi assinada justamente por Gilberto Freyre denominado A atitude brasileira, dizendo:

Não há exagero em dizer-se que no Brasil vem se definindo uma democracia étnica contra a qual não prevaleceram até hoje os esporádicos arianismos ou os líricos, embora às vezes sangrentos melanismos que, uma vez por outra, se têem manifestado entre nós. Há decerto entre os brasileiros preconceito de cor. Mas estão longe de constituir o ódio sistematizado, organizado, arregimentado, de branco contra preto ou de ariano contra judeu ou de indígena contra europeu que se encontra em outros países de formação étnica e social semelhante à nossa. [Freyre encerra seu texto argumentando ainda que] "devemos estar vigilantes, os brasileiros de qualquer origem, sangue ou cor, contra qualquer tentativa que hoje se esboce no sentido de separar, no Brasil, "brancos" de "africanos" (Quilombo no. 1. dez. de 1948. Apud ROSA, 2007: 83) 
Este espaço em que Freyre fez a defesa de suas ideias foi aberto a todos que quisessem debater este assunto. Para o pesquisador Domingues o fato de Freyre ter escrito para o jornal Quilombo pode estar relacionado o objetivo daqueles que o produziam de "livrar o jornal de qualquer possibilidade de ser estigmatizado negativamente. [...], portanto, de investir na formação de uma cruzada multicolor também foi uma tática utilizada por Quilombo para se eximir da imagem de intolerância ou sectarismo junto à opinião pública." (DOMINGUES, 2008: 268) Rosa aponta em seu texto, que para Macedo o jornal Quilombo conseguiu:

“dar vazão às ideias, propostas e representações de intelectuais (negros e brancos) e ativistas negros a respeito da população afro-brasileira dos anos 1940 e 1950." É a partir dessa observação que podemos compreender, por exemplo, a presença da discussão feita por Gilberto Freyre. (ROSA, 2007: 84)

É importante perceber como essa coluna era indispensável para o jornal e como coloca Domingues "o ideal da democracia racial perpassou vários números de Quilombo. No geral é possível afirmar que a folha compactuava, ao mesmo tempo, negociava na orbita desse ideal." (Domingues, 2008: 268) e seguindo as ideias do autor, o que nos leva a compreender é que esse ideal de democracia racial foi muitas vezes moldado para se encaixar no debate defendido pelo TEN, ou seja, o TEN mantinha uma relação ambígua com esse ideal. 
Não podemos negar que muitas são as possibilidades dessa relação uma das quais quem nos esclarece é Petrônio Domingues, pois para ele:

[...] o jornal empreendeu uma política de colaboracionismo racial. Para fortalecer a "obra de valorização social dos brasileiros de cor", era necessário aludir-se com deferência aos presumíveis aliados brancos que levantavam a bandeira antiracista, tanto no campo político quanto intelectual. (DOMINGUES, 2008: 268)

Outro fator que pode ter contribuído para essa relação é referente à questão financeira, o que poderia ter aberto as portas do editorial para a "campanha publicitária para ampliar o número de assinantes. (DOMINGUES: 267)

Como podemos perceber são muitas as possibilidades dessa relação entre o jornal e a dita "luta contra a democracia racial". As várias vozes presentes no periódico e as várias interpretações que essa coluna, assim como todo o jornal, deixava uma visão dualista dos temas defendidos pelo TEN, o que acabam levando o pesquisador deste tema se manter sempre alerta e aberto às implicações que o tema atrai sobre si.

Este jornal também foi palco para as reivindicações e defesa da mulher negra dentro da sociedade. A coluna "Fala Mulher" era de autoria de Maria Nascimento, e o que ela pretendia era conversar com suas "irmãs" de cor, onde escreveu no primeiro número, 
Cadernos de Clio, Curitiba, n. ${ }^{\circ}$ 3, 2012

Discutiremos nossos problemas, minhas patrícias, com a simplicidade de verdadeiras irmãs e amigas que se amam. [...] Vamos, pois, conversar e atuar como pessoas que só não estão mais integradas neste século de civilização e progresso por falta de oportunidades. Oportunidades que doravante lutaremos para conseguir. (Quilombo, dezembro, de 1948. Apud DOMINGUES, 2008: 280)

Neste espaço Maria Nascimento procurava falar de todos os assuntos que poderiam interessar a mulher negra. Através dessa coluna o jornal também procurou defender a causa das empregadas domésticas. E como ela se propunha lutar para que haja mais respeito pela mulher negra dentro da sociedade, para a autora dessa coluna era preciso que essa própria mulher tomasse consciência de sua importância e liderasse o seu papel na história. (DOMINGUES, 2008)

Com relação à luta das empregadas domesticas jornal Quilombo publicou em janeiro de 1950 uma matéria denominada "Precisam-se de Escravas", onde aparece "A verdade é que a empregada doméstica é uma lembrança amarga dos anos de escravatura" (QUILONBO, fevereiro, de 1950 6p.9. Apud ROSA, 2007: 86) As reivindicações para essa área gerou a criação de um Conselho Nacional das Mulheres Negras, criado pelo TEN, onde eles propunham a regulamentação das empregadas domésticas.

Nessa coluna destinada à mulher negra Maria Nascimento também defendia uma nova postura para as suas "irmãs" de cor, em 
uma matéria ela utiliza a figura de Ruth de Souza para exaltar esse ideal a ser assumido,

Além de intérprete dotada de rara sensibilidade e poder expressional, ela é uma personalidade forte e interessante, estudiosa de todos os problemas de arte, inteligência alerta e sequiosa de aprender sempre mais. Exemplo da nova mulher negra. (Quilombo, dezembro de 1948, p.6. apud DOMINGUES, 2008: 281)

As ações implantadas pelo jornal procuravam divulgar a "denuncia de racismo que grassava em entidades filantrópicas, escolas, instituições filantrópicas [...] (DOMINGUES: 277)

Essas reportagens escritas e debatidas por Maria Nascimento procuravam divulgar abusos e cobravam atitudes por parte das autoridades. No artigo "Discriminação nas obras sociais" o jornal,

[...] tornou público que o "Catálogo de Obras Sociais do Distrito Federal”, editado pela Legião Brasileira de Assistência, em 1948, apresentava uma relação de instituições de assistência social - dispensários, colégios, orfanatos e asilos - que não aceitavam o ingresso de negros. (DOMINGUES, 2008: 278)

Petrônio Domingues acredita que:

O jornal aproveitava as denuncias dos casos de "preconceito racial" para reforçar sua concepção, segundo a qual, o problema do negro no Brasil tinha natureza racial, fundamentalmente, e social, secundariamente. Nesse sentido, os negros eram vítimas de racismo independentemente de sua condição social. (DOMINGUES, 2008: 279) 
$\mathrm{O}$ que podemos perceber dessa postura do jornal Quilombo, é que durante muito tempo a imprensa negra foi apresentada como "imprensa adicional", ou seja, os jornais desenvolvidos pelos movimentos negros, não só o jornal Quilombo, muitas vezes passava despercebido ou eram pouco valorizados ${ }^{5}$. O que levou o Quilombo a se posicionar

\begin{abstract}
"como um instrumento que prefaciou através de seus textos e ao longo de seus dois anos de existência, grande parte da parte da ação proposta pelo Teatro Experimental do Negro. Ele desempenhou o papel de colocar parte dos termos que envolviam o debate da questão racial no Brasil” (ROSA, 2007: 84)
\end{abstract}

Para Munanga e Gomes, o debate que o jornal levantou nos anos em que esteve em circulação foi "uma produção muito diferente dos outros jornais militantes que o antecederam" e estes autores estão de acordo com as falas do sociólogo Antônio Sérgio Guimarães sobre o Quilombo, quando este diz que "talvez o mais importante motivo dessa diferença tenha sido a sua inserção e sintonia com o mundo cultural brasileiro e internacional." (MUNANGA, GOMES, 2006: 122)

Compreendemos também que as propostas as quais o jornal se empenhou foram audaciosas e muitos desses debates acabaram entrando em contradição dentro do próprio jornal, como

\footnotetext{
${ }^{5}$ Com relação à considerar a imprensa negra como "Imprensa adicional" ler BASTIDE, R. “A Imprensa Negra do Estado de São Paulo”. Estudos AfroBrasileiros. São Paulo, Perspectiva,1983.
} 
aparece "Mas páginas de Quilombo, que abrigava de forma democrática uma pluralidade de perspectivas, já exibem a tensão entre o discurso de colunistas convidados que viam a democracia racial como algo que "vêm se verificando entre nós desde dias remotos"6 e um outro discurso, crítico, de editorial de primeira página: "Democracia de cor não deve nem pode ser apenas um luxo da nossa Constituição, um slogan sem conteúdo e sem efetividade na existência cotidiana do povo brasileiro ${ }^{7}$." (NASCIMENTO, 2003: 8)

Como vimos os debates dentro do jornal acabavam por mostrar os dois lados da questão, e cabe ao pesquisador/historiador trabalhar esses embates de forma a compreender estes discursos presentes neste período de grande importância para o Brasil.

Mas o que não podemos deixar de reconhecer é a luta e a qualidade do produto que foi o jornal Quilombo dentro da sociedade internacional, a carta de Thomé Agostinho das Neves de Luanda (Angola) endereçada a Abdias Nascimento. "Mãos amigas fizeram chegar diante dos meus olhos o jornal QUILOMBO que circula no Brasil". [...] Hoje mesmo li os números $1^{\circ}$ a $4^{\circ}$. Que me inteiraram do que desejava saber da vida social, cultural e artística do negro no Brasil. (Quilombo, janeiro de 1950. Apud DOMINGUES, 2008:

\footnotetext{
${ }^{6}$ Gilberto Freyre, "A atitude brasileira”, na coluna Democracia Racial. Quilombo $\mathrm{N}^{\mathrm{o}} 1, \mathrm{p} 8$.

${ }^{7}$ Abdias Nascimento, "Candidatos negros e mulatos" Quilombo nº, p1.
} 
279) e nacional ${ }^{8}$. As várias falas encontradas dentro dele mostram como este contribui para um debate complexo, que mobilizou diferentes personagens no cenário brasileiro naquele contexto.

\section{Bibliografia}

ABREU, Martha. "Outras histórias de Pai João: conflitos raciais, protesto escravo e irreverência sexual na poesia popular (18801950)" in Afroasia, (31) 2004. Acessado: 30/01/09. Disponível em: www.historia.uff.br/stricto/2007/02_marthaabreu.html ou www.afroasia.ufba.br/edicaoTxt.php?codEd $=27$

AZEVEDO, Célia Maria Marinho de. Abolicionismo Estados Unidos e Brasil, uma história comparada (século XIX). São Paulo. Annablume, 2003.

${ }^{8}$ Sobre a recepção do jornal, A carta de Durvalino Alves da Silva, de Nova Aliança (SP) endereçada a Abdias Nascimento diz: Prezado Sr. Li uma das edições do nosso Jornal Quilombo - vida, problemas e aspirações. Li com amor e carinho porque trata-se exclusivamente da educação social dos nossos irmãos de cor. Sinto-me até acabrunhado em escrever estas linhas porque sou inculto, mas orgulho-me porque esta educação que não alcancei, meus filhos estão alcançando. [...] O número de Quilombo que li foi enviado por uma irmã de cor à minha filha, a qual estuda na faculdade de Comércio em S. José do Rio Preto, Estado de S. Paulo. Pretendo fazer dos meus filhos batalhadores incansáveis em beneficio dos nossos irmãos. (Quilombo, Julho de 1949. Apud DOMINGUES, 2008: 279)

Por essa carta somos levados a reconhecer que o TEN e o Quilombo era sim um formador de opiniões e semeador do orgulho e pertencimento a cor negra. 
BASTIDE, Roger. "A Imprensa Negra do Estado de São Paulo". Estudos Afro-Brasileiros. São Paulo, Perspectiva,1983. Disponível em:

moodle. stoa.usp.br/mod/resource/view.php?id=43513

BITAR, Viana Larissa. Democracia racial e cultura popular. In: ABREU, M, MATTOS, Hebe. Ensino de História: conceitos temáticas e metodologia. Rio de Janeiro. Casa da Palavra, 2003.

CARDOSO, Fernando Henrique. Capitalismo e escravidão no Brasil meridional: o negro na sociedade escravocrata do Rio Grande do Sul. Rio de Janeiro, Paz e Terra, 1977.

COSTA, Emília Viotti da. Da democracia à república: momentos decisivos. São Paulo, UNESP. 1999.

DOMINGUES, Petrônio. Quilombo (1948-1950): uma polifonia de vozes afro-brasileiras. In: Ciências \& Letras. N. 44, 2008, p. 261289. Acessado: 30/01/09 Disponível em:

www1.fapa.com.br/cienciaseletras/pdf/revista44/artigo13.pdf Movimento negro brasileiro: alguns apontamentos históricos. In: Revista Tempo, 2007. Acessado: 20/02/09. Disponível em: www.scielo.br/pdf/tem/v12n23/v12n23a07.pdf A crisálida do teatro negro no Brasil. Disponível em: www.palmares.gov.br/sites/000/2/download/.../revista3-52.pdf Acessado: 20/02/09. 
FREYRE, Gilberto. Casa Grande e Senzala Formação da família brasileira sob o regime da economia patriarcal - 51.ed -. São Paulo: Global, 2006.

GUIMARÃES, Antonio Sérgio Alfredo. Depois da democracia racial. In: Tempo Social USP. (18) 2006. Acessado: 01/03/09. Disponível em:

www.fflch.usp.br/.../temposocial/mostraArtigo.php?id=387

Democracia racial. Disponível em:

www.fflch.usp.br/sociologia/asag/Democracia\%20racial.pdf Acessado: 01/03/09

GOMES, Thiago de Melo. Um espelho no palco. Campinas, Unicamp, 2004.

GOMES, Thiago de Melo. Negros Contando (e Fazendo) sua História: Alguns Significados da Trajetória da Companhia Negra de Revista (1926). In Estudos Afro-Asiáticos, 2001. ano 23. Disponível em: www.scielo.br/pdf/eaa/v23n1/a03v23n1.pdf Acessado: 03/03/09.

IANNI, Octávio. As metamorfoses do escravo. São Paulo: Difel, 1962.

MAIO, Marcos Chor. O Projeto Unesco e a agenda das ciências sócias no Brasil dos anos 40 e 50. RBCS. Vol 14 n 41 outubro de 1999. Disponível em:

www.scielo.br/scielo.php?pid=S0102-69091999000300009...sci... 
MUNANGA, KAbengele, GOMES, Nilma lino. O negro no Brasil de hoje. São Paulo. Ação Educativa, 2006.

MENDES, Miriam Garcia. O negro e o teatro brasileiro. São Paulo, Hucitec, 1993.

NASCIMENTO, Abdias. Teatro Experimental do Negro: trajetória e reflexões. In: Estudos Avançados. 18 (50) 2004. Acessado: 03/03/09 Disponível em:

www.scielo.br/scielo.php?script=sci_arttext

- Teatro e realidade brasileira. Revista Civilização brasileira, n 2, s/d.

QUIOLOBO: Vida, Problemas e Aspirações do Negro. Edição facsimilar, dirigido por Abdias Nascimento, Rio de Janeiro, $\mathrm{n}^{\mathrm{o}} 1$ a 10, dezembro de 1948 a Julho de 1950. Editora 34, 2003, $2^{\circ}$ edição.

ROSA, Daniela Roberta Antônio. Teatro Experimental do Negro: estratégia e ação. Dissertação de Mestrado. Campinas UNICAMP, 2007.

SOUZA, Silvia Cristina Martins de. O palco como tribuna: uma interpretação de "O Demônio Familiar", Curitiba, Aos Quatro Ventos, 2002.

SOUZA, Silvia Cristina Martins de, "Cantando e encenado a abolição e a escravidão". IV Encontro Escravidão e Liberdade no Brasil Meridional. Curitiba-PR APICURI, 2009. 